\title{
Experiments and Numerical Simulations of Vertical Flame Spread on Charring Materials at Different Ambient Temperatures
}

\author{
JOHAN MANGS, and SIMO HOSTIKKA \\ VTT Technical Research Centre of Finland \\ P.O. Box 1000 \\ FI-02044 VTT, Finland
}

\begin{abstract}
A new experimental apparatus for measuring flame spread rates at different ambient temperatures is presented. The $2 \mathrm{~m}$ long sample is pre-heated with air to the desired temperature, ignited from below with a small propane burner, and flame spread is monitored with thermocouples at the surface of the sample. The rate of vertical concurrent flame spread as a function of ambient temperature is determined on cylindrical Birch rod samples and on polyvinylchloride cable samples. Corresponding flame spread scenarios are numerically simulated using an axi-symmetric solution of the flow field and a pyrolysis model with parameters estimated from thermogravimetric and cone calorimeter experiments. The simulation model was able to predict the flame spread rates within the uncertainties associated with the experiments and postsimulation analysis of the spread rate.
\end{abstract}

KEYWORDS: flame spread, pyrolysis, experiments, Birch wood, PVC, cables, modeling.

\section{INTRODUCTION}

Concurrent flame spread is the fastest of the flame spread modes where the local flame heat transfer controls the spread rate. Despite the decades of research, it is not understood as well as the counter-current flame spread, for which several analytical and numerical models have been developed. In concurrent flame spread, the rate of spread depends on the coupled time-dependent heat and mass transfer processes in the gas and solid, and the detailed understanding of these processes is still developing. Carrier et al. investigated the effects of the sample properties on the wind-aided flame spread rate using a 2-dimensional model of the Steiner tunnel test [1]. Fernandez-Pello used a boundary layer approximation to solve the vertical flame spread on infinitely wide fuel surfaces [2]. Models including fuel burnout and the consequent steady-state flame spreading have been developed by Markstein and de Ris [3] for textiles and by Grant and Drysdale [4] for building materials.

Flame spread has been one of the central topics of the fire safety research of Finnish nuclear power plants [5-7] due to the risks associated with huge amounts of electrical cables and other solid fire loads. The fire spreading on pre-heated cables is one of the plausible fire scenarios even for those cables consisting of flame-retarded materials because many of the flame retardants degrade at temperature range $200-300{ }^{\circ} \mathrm{C}$. Motivated by the need to understand the effect of the ambient temperature on the flame spread process, a new experimental apparatus has been developed for the measurement of flame spread at different ambient temperatures ranging from room temperature up to temperatures close to auto-ignition temperatures of most solid fuels. The present paper describes in brief the new apparatus and results from flame spread experiments on cylindrical Birch rods and electrical polyvinylchloride (PVC) cables. A detailed description of the experimental apparatus and initial results are reported in [8].

The new apparatus is also used to provide data for the validation of numerical simulation. The challenge of the numerical flame spread simulations in real geometries comes from the order-of-magnitude difference between the scales of local flame heat transfer and the affordable geometry. Xie and DesJardin [9] have proposed the solution where subgrid scale (SGS) properties of the local flame properties are generated using the direct numerical simulation (DNS) of the flame spread, demonstrating the process for 2-D simulations of polymethylmethacrylate (PMMA). In the present work, axi-symmetric simulations of the flame spread on Birch rods are performed using Fire Dynamics Simulator [10] and a pyrolysis model with parameters estimated from small scale experiments. The simulation results are compared with experiments and the implications for the future applications are discussed. 


\section{EXPERIMENTAL}

\section{Structure and Operational Principles of the Apparatus}

Schematic pictures of the apparatus are shown in Fig. 1. The apparatus consists of a heating channel and a test channel (width $300 \mathrm{~mm}$, depth $330 \mathrm{~mm}$, height $2940 \mathrm{~mm}$ ), separated from each other by a thin stainless steel sheet and connected to each other at the upper and lower parts of the channels. The system is insulated with a $100 \mathrm{~mm}$ thick Kaowool layer between $0.5 \mathrm{~mm}$ stainless steel plates. There is a door on the front side to the channels, an air inlet in the upper part of the heating channel and a smoke outlet at the top of the test channel. The device is pivoted from a massive steel support at its lower end, and can be used in either the vertical or horizontal position. This report considers operation in the vertical position only.

In the upper part of the heating channel is a $7.0 \mathrm{~kW}$ heating resistor and a fan for heating and circulating the air. During the heating phase, the air inlet and roof hatches are closed and the sample is heated by hot air circulating inside the cabinet (Fig. 2a). During the flame spread experiment, the fan draws in fresh air through the intake in the upper part of the heating channel. The air flows through the heater to the test channel, and fire effluents exit through the outlet (Fig. 2b). The upper opening connecting the channels is closed during the experiment. The controls for the rate of air flow and temperature are located outside of the cabinet.

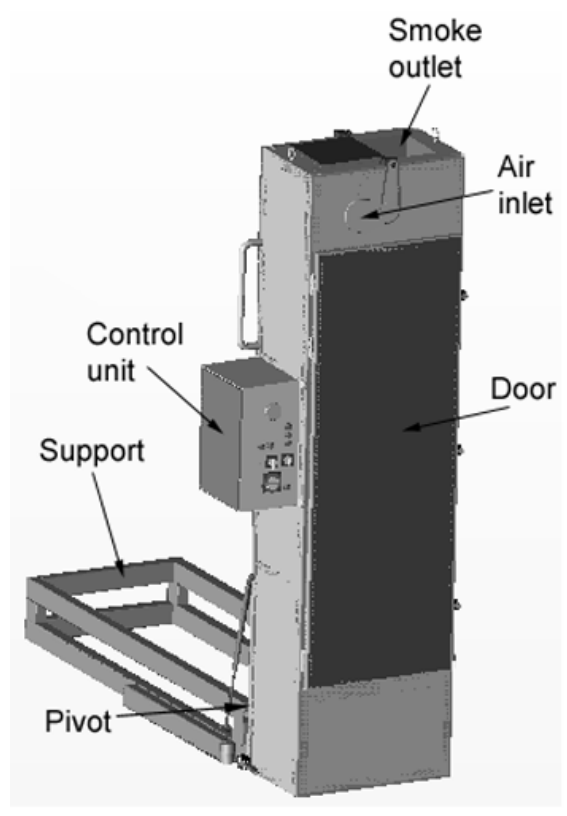

(a)

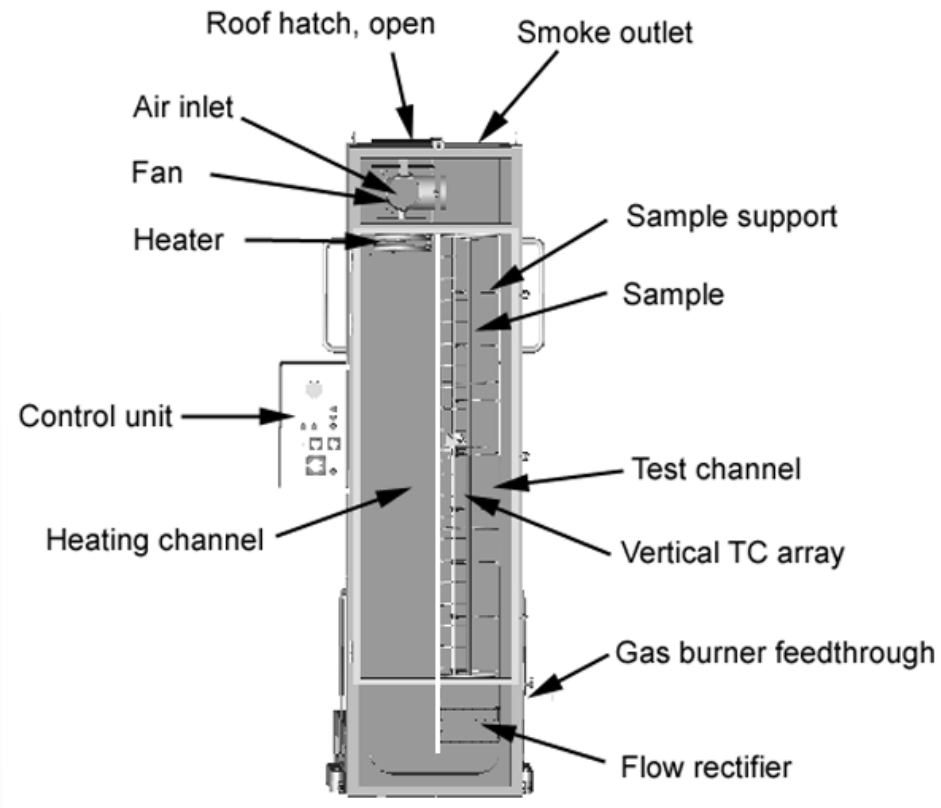

(b)

Fig. 1. Structure of the flame spread apparatus: (a) general view; (b) cross-section with essential features.

The maximum heat release rate from samples can be estimated from the heat release per unit area of solids $\left(100-200 \mathrm{~kW} / \mathrm{m}^{2}\right)$ and from the oxygen consumption calorimetry $(2.94 \mathrm{MJ} / \mathrm{kg}$ of dry air). It is expected to remain below $100 \mathrm{~kW}$ (mostly below $20 \mathrm{~kW}$ ), which corresponds to mean average vertical air flow velocities smaller than $0.3 \mathrm{~m} / \mathrm{s}$ (mostly below $50 \mathrm{~mm} / \mathrm{s}$ ). A minimum flow rate of $0.3 \mathrm{~m} / \mathrm{s}$ is recommended as the air should circulate to some extent to avoid damaging the resistors. This air flow can also provide sufficient oxygen for burning during the experiment. A flow rate of $0.3 \mathrm{~m} / \mathrm{s}$ corresponds to a volumetric flow rate $30 \mathrm{dm}^{3} / \mathrm{s}$ in the $0.3 \mathrm{~m} \times 0.33 \mathrm{~m}$ channel. The air flow into the test channel is straightened with a flow rectifier consisting of two $1 \mathrm{~mm}$ steel wire screens above and below a honeycomb, with cell length of $50 \mathrm{~mm}$ and diameter of $5 \mathrm{~mm}$. 


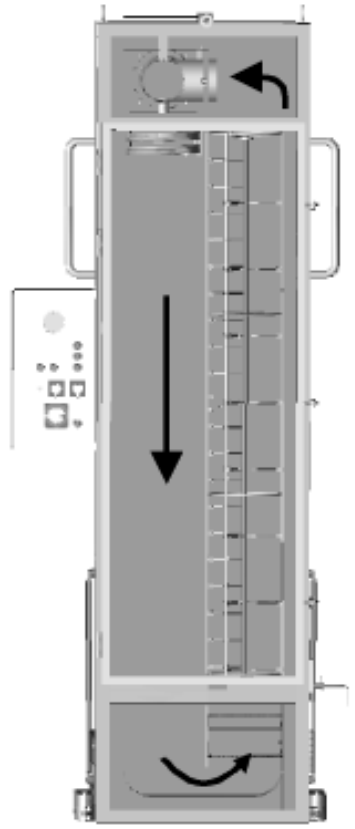

(a)

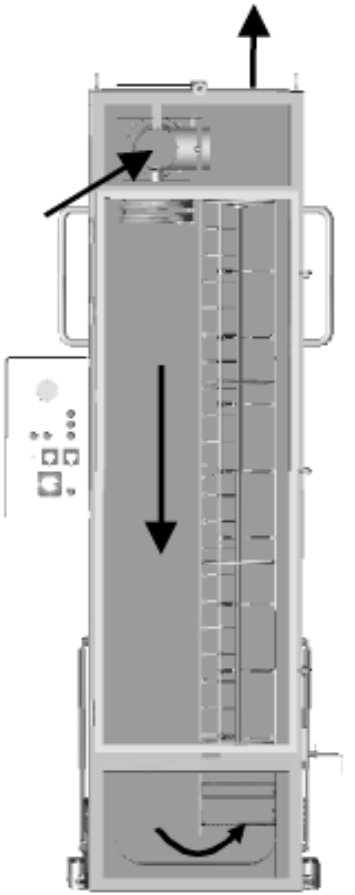

(b)

Fig. 2. (a) Circulation of air during heating phase; (b) fresh air intake to heating channel and fire effluent outlet from top of test channel during experiment, upper opening connecting the channels closed.

The $2 \mathrm{~m}$ long sample is suspended from its upper end in a support and kept in place in the centre of the test channel with pins at $250 \mathrm{~mm}$ vertical intervals. The temperatures at the boundary between the gas and the sample surface are measured at $100 \mathrm{~mm}$ vertical intervals with $0.25 \mathrm{~mm}$ Type-K thermocouples T1-T19 supported by ceramic insulator tubes shielded with steel tubes. The sample is ignited from below with a helical shaped propane burner and a glow wire.

\section{Experimental Procedure}

During the heating phase, the sample is heated with air circulating at the highest possible speed $(2.6 \mathrm{~m} / \mathrm{s}$ at room temperature in the test channel). Examples of times to reach the desired temperature are 9 min to reach an average temperature of $90{ }^{\circ} \mathrm{C}$ and 54 min to reach $304{ }^{\circ} \mathrm{C}$. When the desired temperature is reached, transition from the heating phase to the flame spread experiment consists of the following sequence:

1. heating is temporarily turned off

2. the air flow is lowered to $0.3 \mathrm{~m} / \mathrm{s}$ air flow

3. heating is turned on

4. the heating of glow wire is turned on

5. the propane gas line is opened

6. burner ignition and sample in flame contact

7. the roof hatch is opened

Maximum gas temperatures in the test channel are measured immediately before turning the heating temporarily off and lowering air flow rate. After this the temperatures in the test channel decrease somewhat until the burner is ignited and the lower end of the sample is in flame contact. This temperature drop depends primarily on how fast the operator gets through with the abovementioned sequence, and is typically $5-12{ }^{\circ} \mathrm{C}$. The temperature at the start of the flame spread experiment is calculated as the average temperature in the test channel immediately before turning the burner on. The propane burner is on until the 
thermocouples show that the sample has ignited and flame spread is established. Fig. 3a shows a sequential temperature rise as the flame front proceeds along a cylindrical Birch rod pre-heated to $197^{\circ} \mathrm{C}$.

The heating phase is assumed to be slow enough so that the sample is in thermal equilibrium with the channel gas temperature when ignited. For $8 \mathrm{~mm}$ Birch rods, the conduction time scale $R^{2} / \alpha(R$ is sample radius and $\alpha$ is thermal diffusivity) is about $60 \mathrm{~s}$ and usually shorter than the duration of the heating phase. The pre-heating of the interior of the sample was checked experimentally by placing a $0.25 \mathrm{~mm}$ thermocouple inside a $2.5 \mathrm{~mm}$ hole drilled to the centre of the $8 \mathrm{~mm}$ rod and plugged with a wooden stick. At the time of the burner ignition, the temperatures inside the sample were at most $5-6{ }^{\circ} \mathrm{C}$ lower than the surface temperature. A similar procedure was attempted with the cable samples but failed due to tightening difficulties of the thermocouple inlet due to softening of the cable material at higher temperatures.

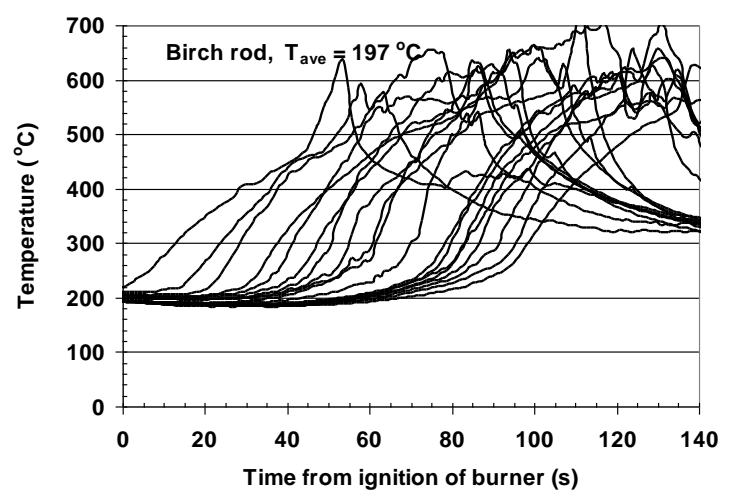

(a)

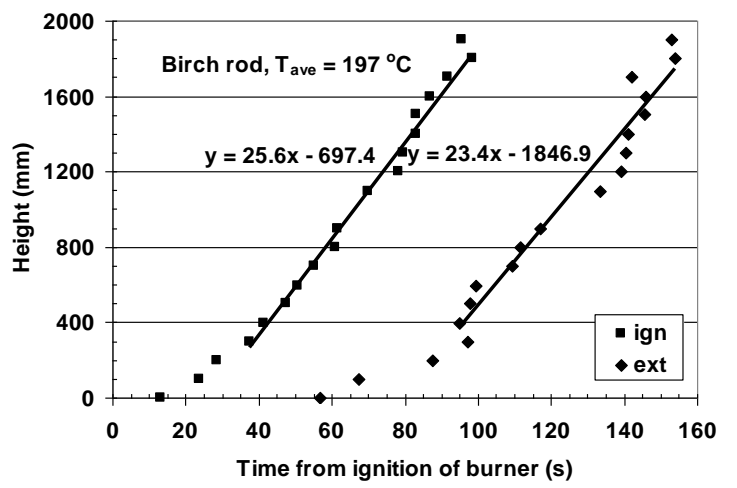

(b)

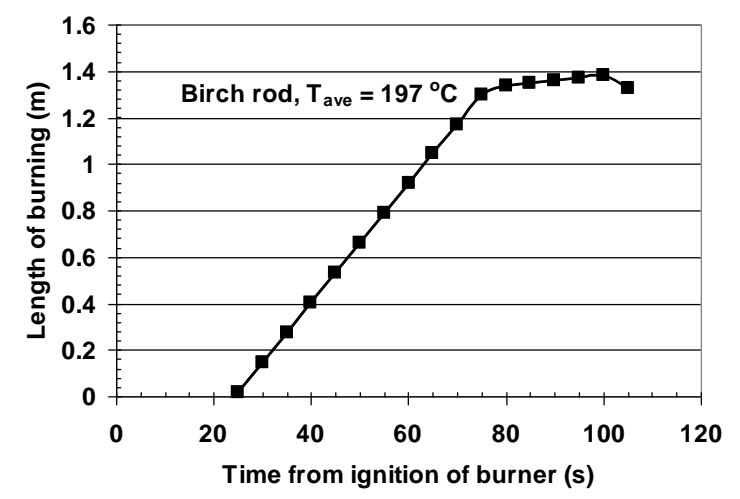

(c)

Fig. 3. Flame spread on a cylindrical Birch sample: (a) temperature-time curves; (b) straight line fit to height-time plot for ignition and extinction; (c) length of burning as a function of time. 
The rate of flame spread on a surface is defined as the rate of movement of the ignition front [11]. Here it is deduced from the measured surface temperatures by specifying a temperature threshold criterion for the presence of the ignition front. Visual inspection of the temperature-time curves indicated that the temperature rise is steep for most of the curves around $300{ }^{\circ} \mathrm{C}$. The propagation of the ignition front to a certain height is thus estimated by determining the moment when the corresponding thermocouple indicated a temperature rise above $300^{\circ} \mathrm{C}$. Plotting the ignition front height as a function of time (Fig. $3 \mathrm{~b}$ ), shows that after some time, the flame spread rate approaches a constant value. Fitting a straight line to this part of the curve gives the steady-state flame spread rate as the slope of the line. The possible influence of the chosen temperature threshold was determined for some experiments using an additional threshold of $400{ }^{\circ} \mathrm{C}$. The same slopes were obtained for both thresholds.

The location of the "extinction front" can be determined in the same way by plotting the moment when the temperature curve is clearly decreasing. However, the extinction of the sample is less symmetrical than the ignition, especially for cable samples, leading to larger scatter from the linear in the height vs. time plot. In the extinction phase the thermocouples are no longer in well-defined contact with the sample surface, but may e.g. be surrounded by charred material or in free space without contact with the specimen. This introduces additional uncertainty about the extinction front estimation. As the maximum temperatures differ for the different thermocouples, the temperature threshold is chosen to be some well-defined point on the decreasing temperature curves that can be determined for all thermocouples. An example for the same Birch rod is given in Fig. $3 \mathrm{~b}$ with a temperature threshold of $500{ }^{\circ} \mathrm{C}$. The possible influence of the choice of temperature threshold was estimated in some of the PVC cable experiments. The "extinction front speed" was determined from height-time plots for different temperature thresholds. The deviation from mean was rather small, about $4 \%$. Subtracting the obtained linear height of extinction from the height of ignition one obtains an approximate length of burning sample (pyrolysis length), as shown for the same Birch rod sample in Fig. 3c. If the flame front and extinction front move with the same speed, a pyrolysis region of constant height can be observed moving upwards the sample.

From the fluid dynamics viewpoint, the specimen is placed inside a relatively narrow channel with a small forced flow upwards. The influence of these conditions was quantified by carrying out a series of experiments with a similar set-up in free space at room temperature. Test samples were $0.8 \mathrm{~m}$ long Birch rods of different diameters. When the initially dry samples were assembled in the test rack and ignited, the sample moisture increased close to $1 \%$ wt. Rate of flame spread was deduced from $T>300{ }^{\circ} \mathrm{C}$ criterion in all cases. The results are compared in Fig. 4, where the $2 \mathrm{~m}$ results are from both dry samples and $\sim 6 \%$ moisture samples. Although the data points are few, free space results (1\% moisture) lie between these two $2 \mathrm{~m}$ results, indicating that the influence of the flow conditions inside the $2 \mathrm{~m}$ apparatus are not significantly different from free atmosphere. Furthermore, numerical simulations were performed both in open air and in the apparatus with forced inflow, indicating very small difference in flame spread rates.

\section{Repeatability of Flame Spread Measurements}

Three experiments with MCMK $4 \times 1.5 \mathrm{~mm}^{2}$ PVC cable were carried out intending identical experimental procedures in order to estimate the repeatability of the $2 \mathrm{~m}$ apparatus. The time schedule for the different steps in the experiments was kept the same aiming to an accuracy of one second, which mainly was achieved. Temperature measurements agreed well, as the $95 \%$ confidence level ( 2 standard deviations) for the average temperature in the test channel was $\pm 2{ }^{\circ} \mathrm{C}$ and for a single temperature measurement in the range $\pm 1-5^{\circ} \mathrm{C}$ as shown in Fig. 5, which also presents the uniformity of heating as a function of height.

Based on the three experiments, the average flame spread rate was $11.4 \mathrm{~mm} / \mathrm{s}$ and the standard deviation was $1.2 \mathrm{~mm} / \mathrm{s}(10 \%)$. 


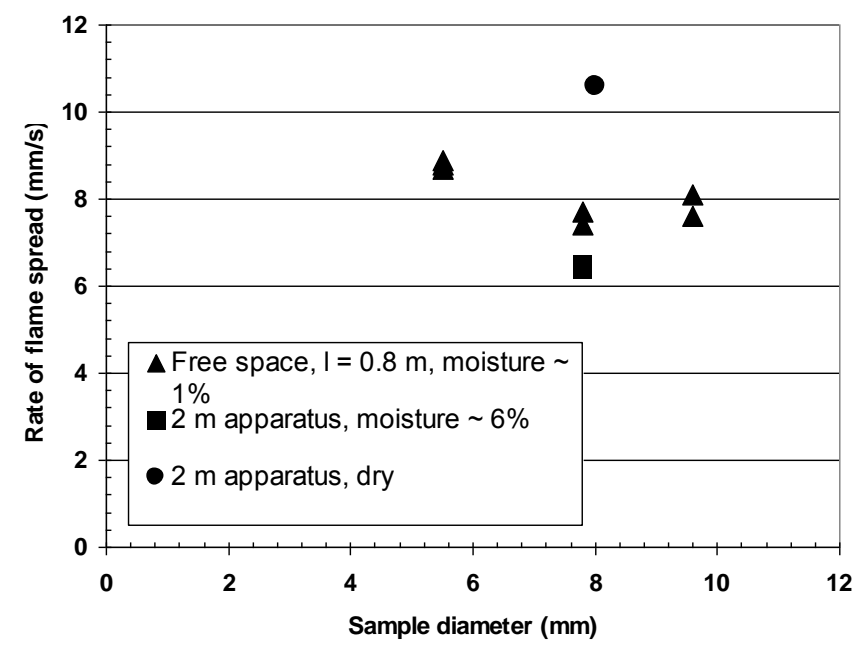

Fig 4. Comparison between rate of flame spread on Birch rods measured in free space and in $2 \mathrm{~m}$ apparatus.

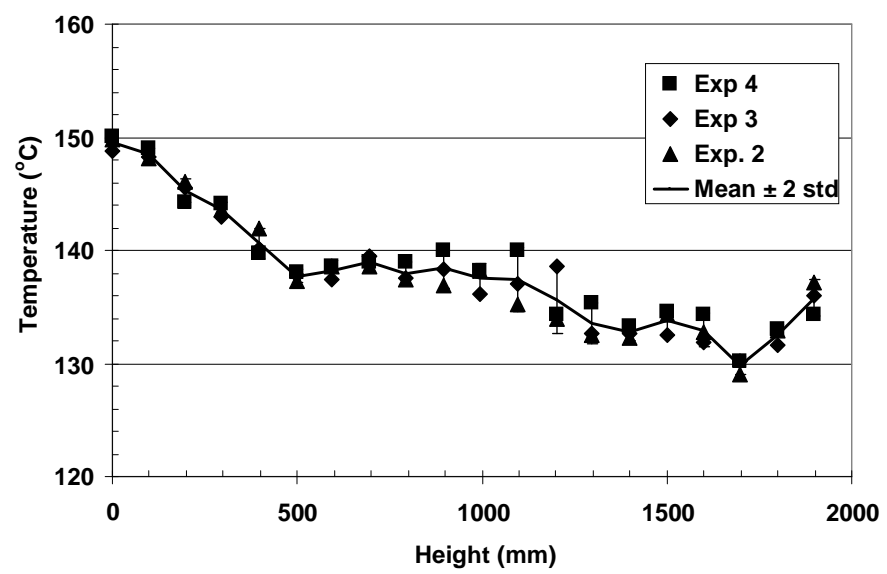

Fig. 5. Measured temperatures immediately before turning glow wire on, mean from three experiments and error bars giving $95 \%$ confidence level of the mean.

\section{RESULTS FROM FLAME SPREAD EXPERIMENTS}

Flame spread experiments with cylindrical Birch rods and PVC sheathed and PVC insulated cables were carried out as described in the previous sections. Table 1 lists the samples, temperature ranges and the propane burner output powers and durations. Birch rods were either stored in ordinary indoor conditions (moisture $6 \%$ wt.) or dried. When the undried samples were heated to $97-181{ }^{\circ} \mathrm{C}$, their moisture content was reduced to $2.3-2.6 \%$ wt. at time of ignition. Cable experiments were carried out with samples stored in ordinary indoor conditions. A slightly higher burner power output was used in the cable experiments to ensure proper ignition, as cable samples do not ignite as easily as wood samples. Deformation of the cable material was observed at temperatures above $200{ }^{\circ} \mathrm{C}$, when the samples were heated in a laboratory furnace. Cable experiments were thus not carried out at temperatures above $195{ }^{\circ} \mathrm{C}$.

The dependence of the flame spread rate and length of burning region on ambient temperature are presented in Figs. 6 and 7, respectively. "Error bars" on the right of the markers indicate maximum temperature in the test channel before starting the flame spread experiment. Vertical error bars for the PVC cable indicate one standard deviation as presented above. At high ambient temperature, both Birch and PVC cable samples were burning simultaneously over their whole length, i.e. the flame front reached the upper end of the sample before the extinction started at the lower end. In these cases, burning length has been denoted as a 
full sample length of $2 \mathrm{~m}$ in Fig. 7, although for a longer sample the true burning length probably would be greater.

Table 1. Main features of flame spread experiments.

\begin{tabular}{|l|c|c|c|c|}
\hline Sample & $\begin{array}{c}\text { Outer diameter } \\
(\mathbf{m m})\end{array}$ & $\begin{array}{c}\text { Temperature range } \\
\left({ }^{\circ} \mathbf{C}\right)\end{array}$ & \multicolumn{2}{|c|}{ Propane burner } \\
\cline { 4 - 5 } & & & $\begin{array}{c}\text { power } \\
(\mathbf{W})\end{array}$ & $\begin{array}{c}\text { duration } \\
(\mathbf{m i n})\end{array}$ \\
\hline Birch rod & 8 & $22-271$ & 200 & $1-1.5$ \\
\hline PVC cable MCMK $4 \times 1.5 \mathrm{~mm}^{2}$ & 13 & $23-188$ & $520-600$ & $1.7-6.2$ \\
\hline PVC cable MCMK $4 \times 6 \mathrm{~mm}^{2}$ & 18.5 & $23-195$ & $520-600$ & $1.7-6.2$ \\
\hline
\end{tabular}

The dependence of flame spread rate on ambient temperature is roughly exponential for both Birch rods and PVC cable samples. As burning length is deduced from flame spread, the same temperature dependence can be seen. The result for PVC cable $4 \times 6 \mathrm{~mm}^{2}$ at $131{ }^{\circ} \mathrm{C}$ seems to be slightly outside the trend, which may be due to uneven flame front propagation. There is no clear difference between the flame spread rates of cables with outer diameters 13 or $18.5 \mathrm{~mm}$.

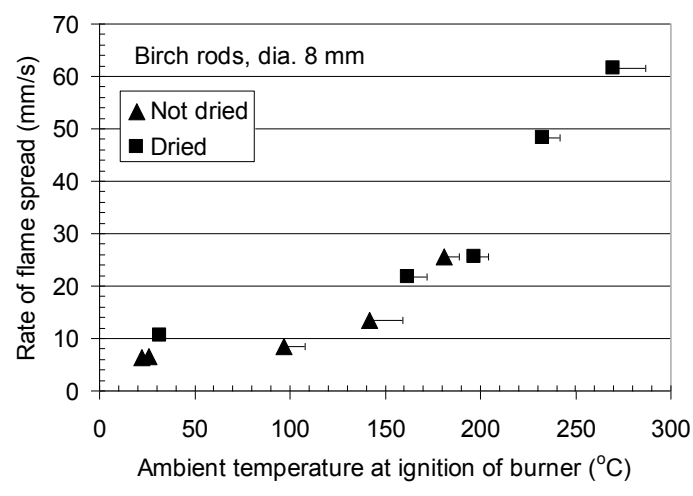

(a)

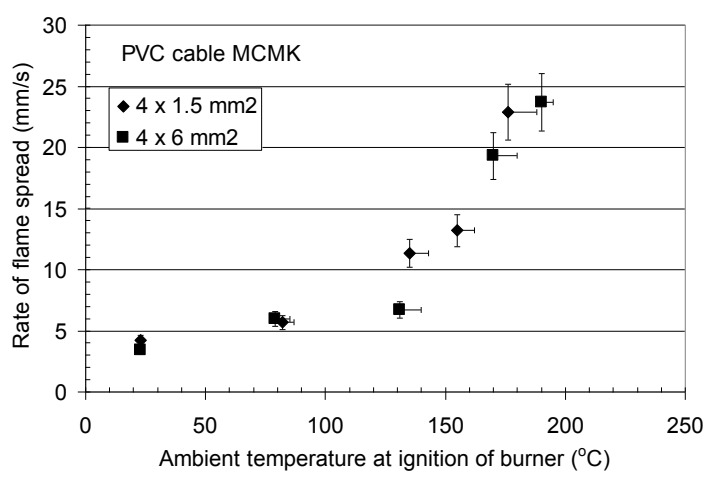

(b)

Fig. 6. Rate of flame spread on $2 \mathrm{~m}$ long samples as a function of ambient temperature: (a) $8 \mathrm{~mm}$ diameter Birch rods; (b) PVC cable MCMK.

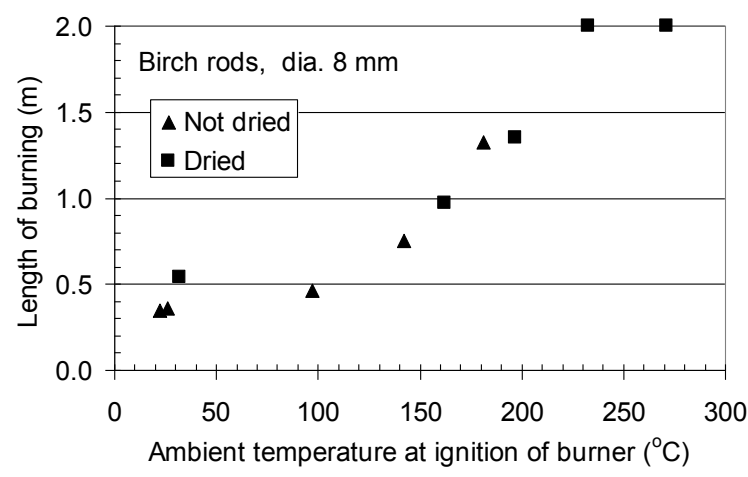

(a)

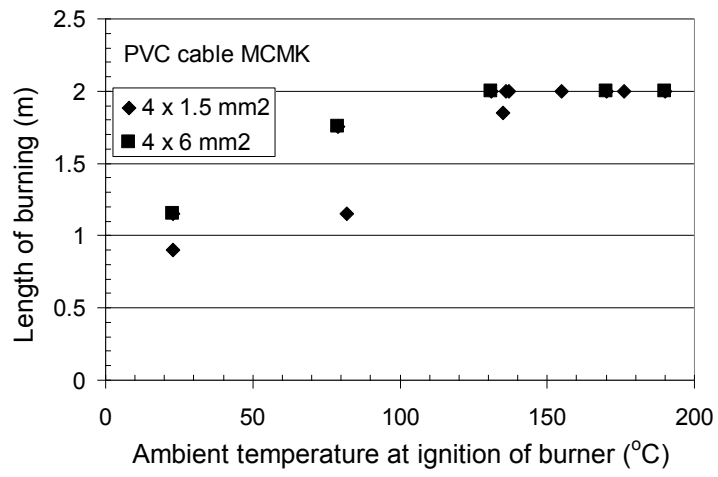

(b)

Fig. 7. Length of burning on $2 \mathrm{~m}$ long samples as a function of ambient temperature: (a) $8 \mathrm{~mm}$ diameter Birch rods; (b) PVC cable MCMK. Cases where flame front reaches the upper end of the sample before extinction starts are all denoted $2 \mathrm{~m}$. 


\section{NUMERICAL SIMULATIONS}

\section{Model Description}

The numerical simulation tool used here was Fire Dynamics Simulator (FDS). The details of the hydrodynamic solver can be found from [10] and are not repeated here. The simulations were performed in DNS-mode and the spatial resolution was set to $1.0 \mathrm{~mm}$ which was small enough to resolve the main characteristic length scales of the flow field. The estimated Kolmogorov scales were mostly longer than 1 $\mathrm{mm}$ but values as low as $0.2 \mathrm{~mm}$ could be found in the boundary layer close to the sample surface. The temporal resolution was determined by Courant and von Neumann numbers. The solutions were forced axisymmetric due to the calculation economics. A global one-step gas phase reaction of fuel and oxygen was assumed with $1 \%$ soot yield and $15 \mathrm{MJ} / \mathrm{kg}$ heat of combustion. The fuel was specified as $\mathrm{C}_{3.4} \mathrm{H}_{6.2} \mathrm{O}_{2.5}$, as suggested by Ritchie et al. [12], corresponding to a reaction

$\mathrm{C}_{3.4} \mathrm{H}_{6.2} \mathrm{O}_{2.5}+3.6 \mathrm{O}_{2} \rightarrow 3.3 \mathrm{CO}_{2}+3.1 \mathrm{H}_{2} \mathrm{O}+0.08 \mathrm{C}$

The computational domain was $0.12 \mathrm{~m} \times 1.8 \mathrm{~m}$ and the corresponding grid dimensions $120 \times 1,800$ (216,000 cells). A sensitivity of the flame spread results to the cell size was studied by performing one Birch rod simulation with $0.5 \mathrm{~mm}$ cell size. The results concerning the flame spread were practically identical to those obtained with $1.0 \mathrm{~mm}$ cells.

In the simulations of the experimental apparatus, a constant upward velocity of $0.3 \mathrm{~m} / \mathrm{s}$ was applied on the bottom boundary and a fixed temperature wall on the outer vertical boundary. An open boundary was specified on the top of the domain. In the simulations of open atmosphere, all three boundaries were specified open. The sample was placed on the central axis of the domain. The temperature inside the solid sample $T_{\mathrm{s}}$ was solved using the one-dimensional heat conduction equation in the direction perpendicular to the sample surface

$\rho_{s} c_{s} \frac{\partial T_{s}}{\partial t}=\frac{1}{r} \frac{\partial}{\partial r}\left(r k_{s} \frac{\partial T_{s}}{\partial r}\right)+\dot{q}_{s}^{\prime \prime \prime}$,

where $\rho_{\mathrm{s}}, c_{\mathrm{s}}$ and $k_{\mathrm{s}}$ are the density, specific heat and thermal conductivity of the material. The boundary condition at the sample surface $(r=R)$ was

$\left.k_{s} \frac{\partial T_{s}}{\partial r}\right|_{R}=\left.\left(k_{g} \frac{\partial T_{g}}{\partial r}+\varepsilon \dot{q}_{r, i n}^{\prime \prime}-\varepsilon \sigma T_{s}^{4}\right)\right|_{R}$,

where $k_{g}$ is the gas phase conductivity, $\varepsilon$ is the surface emissivity and $\dot{q}_{r, i n}^{\prime \prime}$ is the incoming radiative flux.

The pyrolysis model assumes that volatiles are instantaneously released from solid to the gas phase, the solid and the volatiles are in local thermal equilibrium, gaseous products are not condensed, and there are no porosity effects. The chemical source term is computed as

$$
\dot{q}_{s}^{\prime \prime \prime}=-\rho_{s 0} \sum_{\alpha=1}^{N_{m}} \sum_{\beta=1}^{N_{r, \alpha}} r_{\alpha \beta} H_{r, \alpha \beta},
$$

where $\rho_{\mathrm{s} 0}$ is the initial layer density, $H_{\mathrm{r}, \alpha \beta}$ is the heat of reaction associated with the $\beta$ th reaction of the $\alpha$ th material component, and $r_{\alpha \beta}$ is the corresponding reaction rate 
$r_{\alpha \beta}=\left(\frac{\rho_{s, \alpha}}{\rho_{s 0}}\right)^{n_{s, \alpha \beta}} A_{s, \alpha \beta} \exp \left(-E_{s, \alpha \beta} / R T_{s}\right)$

Here $n_{\mathrm{s}, \alpha \beta}, A_{\mathrm{s}, \alpha \beta}$ and $E_{\mathrm{s}, \alpha \beta}$ are the kinetic coefficients.

The simulations were carried out using version 5.4.3 of FDS using the Message Passing Interface (MPI) technique for parallel computing. For this purpose, the computational mesh was divided into six blocks of equal size in vertical direction. The time to complete a typical calculation was approximately $1.6 \mathrm{~h}$ of CPU time per one second of simulated time on a computer server having two quad-core Intel Xeon processors $(3.0 \mathrm{GHz})$.

\section{Material Model for Birch Wood}

Two parallel reactions were assumed; one converting virgin wood to char and gaseous fuel, and another converting moisture to water vapor. Both kinetic and thermal parameters were estimated using a genetic algorithm minimizing the error between the experimental and simulated data [13]. The kinetic coefficients were estimated from thermogravimetric (TGA) experiments in an $\mathrm{N}_{2}$ atmosphere at several heating rates. A comparison of experimental and simulated TGA curves for two heating rates is shown in Fig. 8a. The heating rates are assumed to be sufficiently slow to allow the sample to remain in thermal equilibrium during the heating. The temperature dependent $c_{\mathrm{s}}$ and the heat of reaction were measured with a separate differential scanning calorimeter (DSC) experiment. The remaining thermal parameters were estimated from the mass loss rate results of cone calorimeter experiments on Birch board at $50 \mathrm{~kW} / \mathrm{m}^{2}$ radiation level in air and $\mathrm{N}_{2}$ atmospheres. The results of the fitted model are shown in Fig. 8b. The experimental mass loss rates (MLR) were determined by fitting piecewise-continuous polynomials to the mass curves, paying attention to the transient characteristics. The model captures the change in MLR due to the presence of air by adding the flame heat flux to the thermal exposure. This happens despite the coarse gas phase meshing because a prescribed fraction of the combustion energy is allocated to the radiation source term. There are no $\mathrm{O}_{2}$-dependent reactions in the pyrolysis model.

Despite the number of adjustable parameters, the agreement between the model and experiments is only moderate. The ignition times and average burning rates are close to those measured, but the heights of the first MLR peak is predicted clearly too high in $\mathrm{N}_{2}$. Improving the agreement may require model developments considering things like porosity and two-dimensionality by wood grains. The model parameters are listed in Table 2. The moisture content was set either $1.0 \%$ wt., or zero in those $2 \mathrm{~m}$ simulations where ambient temperature was above $100{ }^{\circ} \mathrm{C}$. Some uncertainty is associated with the application of parameters obtained at a $50 \mathrm{~kW} / \mathrm{m}^{2}$ heating rate to the vertical flame spread situation, where the flame heat flux is typically about $25 \mathrm{~kW} / \mathrm{m}^{2}$. In a similar situation but for white pine samples, Lautenberger [14] reported a $20 \%$ over-prediction in peak MLR and 2 min under-prediction in the timing of the peak. 


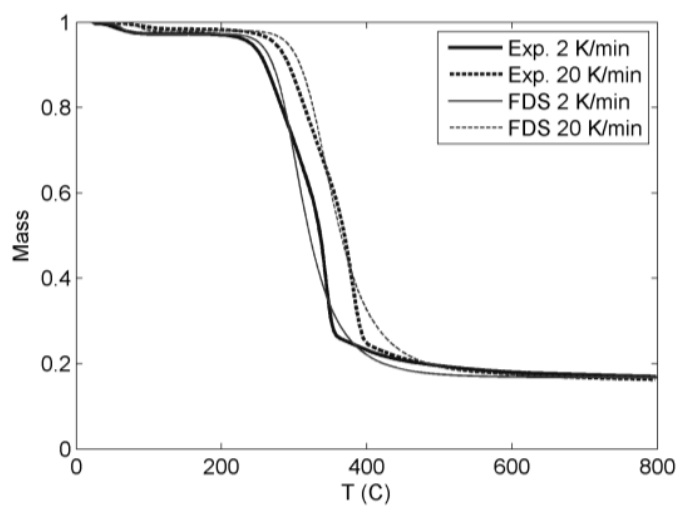

(a)

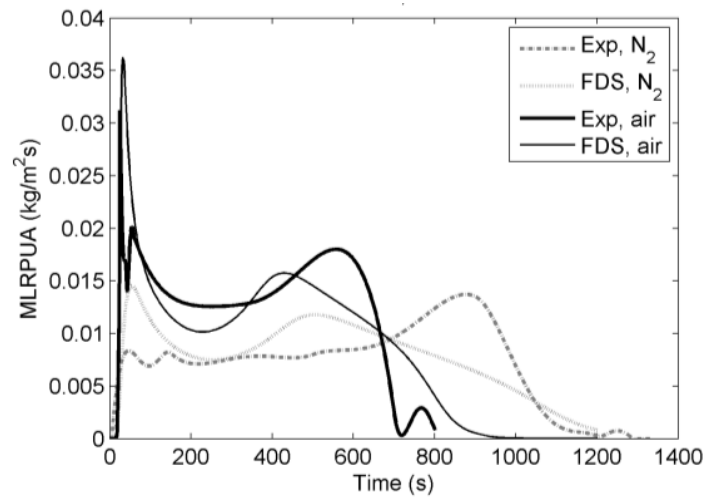

(b)

Fig. 8. Experimental and simulated results for Birch: a) TGA at 2 and $20 \mathrm{~K} / \mathrm{min}$ heating rates in $\mathrm{N}_{2}$ atmosphere; (b) cone calorimeter mass loss rate per unit area (MLRPUA) at $50 \mathrm{~kW} / \mathrm{m}^{2}$ radiation level.

Table 2. Condensed phase parameters for Birch wood simulations.

\begin{tabular}{|l|l|c|c|c|}
\hline Symbol & Parameter & Moisture & Birch & Char \\
\hline$A_{s, x}$ & Pre-exponential factor $(1 / \mathrm{s})$ & $1 \times 10^{13}$ & $7.513 \times 10^{11}$ & - \\
\hline$E_{s, x}$ & Activation energy $(\mathrm{J} / \mathrm{mol})$ & $1 \times 10^{5}$ & $1.61 \times 10^{5}$ & - \\
\hline$n_{s, x}$ & Reaction order & 1.0 & 3.12 & - \\
\hline$v_{s, x}$ & Char yield & 0.0 & 0.22 & - \\
\hline$v_{g, x, f}$ & Fuel yield & 0.0 & 0.78 & - \\
\hline$v_{g, x, w}$ & Water yield & 1.0 & 0.0 & - \\
\hline$c_{s, x}$ & Specific heat $(\mathrm{kJ} / \mathrm{kg} \cdot \mathrm{K})$ & 4.19 & $1.20\left(20^{\circ} \mathrm{C}\right)$ & $0.76\left(235^{\circ} \mathrm{C}\right)$ \\
& & & $1.36\left(180{ }^{\circ} \mathrm{C}\right)$ & $0.82\left(260^{\circ} \mathrm{C}\right)$ \\
& & & $1.42\left(210^{\circ} \mathrm{C}\right)$ & $0.94\left(300^{\circ} \mathrm{C}\right)$ \\
& & & & $1.10\left(450^{\circ} \mathrm{C}\right)$ \\
\hline$H_{r, s, x}$ & Heat of reaction $(\mathrm{kJ} / \mathrm{kg})$ & 2410 & 315 & - \\
\hline & Heat of combustion $(\mathrm{kJ} / \mathrm{kg})$ & 0 & $14.5 \times 10^{3}$ & - \\
\hline$\varepsilon_{v, x}$ & Surface emissivity & 0.8 & 0.85 & 0.95 \\
\hline$k_{s, x}$ & Conductivity $(\mathrm{W} / \mathrm{m} \cdot \mathrm{K})$ & 0.58 & $0.2\left(20^{\circ} \mathrm{C}\right)$ & $0.065\left(20{ }^{\circ} \mathrm{C}\right)$ \\
& & & $0.4\left(400{ }^{\circ} \mathrm{C}\right)$ & $0.2\left(500{ }^{\circ} \mathrm{C}\right)$ \\
\hline$\rho_{x}$ & Density $\left(\mathrm{kg} / \mathrm{m}^{3}\right)$ & 1000 & 606 & 133 \\
\hline$Y_{s, x}$ & Initial mass fraction $(\mathrm{kg} / \mathrm{kg})$ & $0.01 / 0.0$ & 0.99 & 0.0 \\
\hline
\end{tabular}

\section{Results}

For the validation of the proposed model, experiments on Birch rods were simulated. The position of the ignition front (upper edge of the pyrolysis region) at each time step was determined as the highest position where the burning rate exceeded $0.001 \mathrm{~kg} / \mathrm{m}^{2} \cdot \mathrm{s}$. Simulated ignition front positions are shown in Fig. 9a for Birch rods with diameters from 2 to $10 \mathrm{~mm}$ in open atmosphere at $20{ }^{\circ} \mathrm{C}$. Each of the curves shows an initial acceleration phase, after which the flame spread rate slows down a bit, reaching a steady or close-tosteady state. Fitting straight lines to the latter parts of the curves gives us the dependence of the steady flame spread rate on sample diameter. A comparison of simulated and measured results is shown in Fig 9b. The figure also shows simulated and measured flame spread rates for an $8 \mathrm{~mm}$ Birch rod inside the experimental apparatus. The flame spread rates in the diameter range 5.5 to $10 \mathrm{~mm}$ are close to the measured, but not much can be said on the predicted effect of the sample diameter because the strong increase of spread rate is only observed for diameters smaller than those studied experimentally. The difference between the open and closed environment results is correctly predicted. 


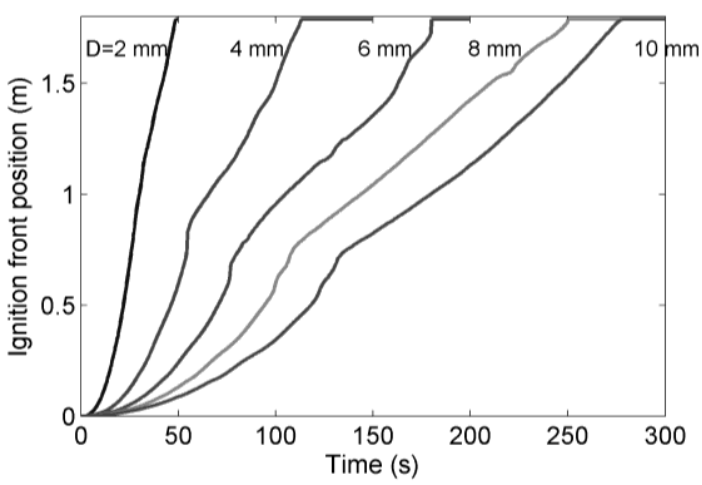

(a)

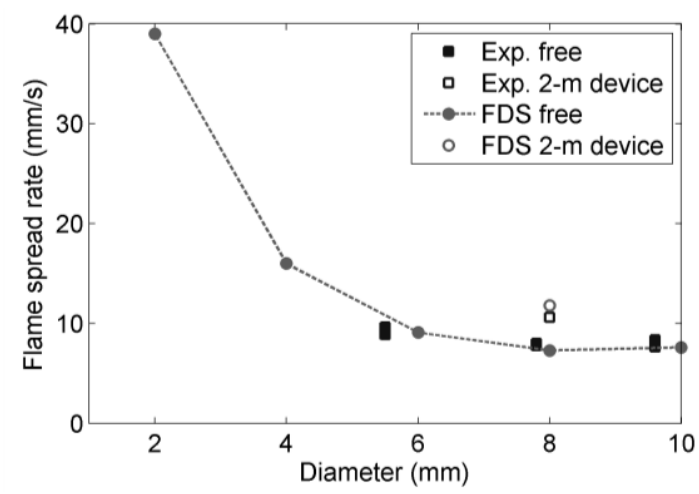

(b)

Fig. 9. (a) Position of the simulated ignition front in open environment simulations with different sample diameters; (b) dependence of the flame spread rate on the diameter.

The capability of the model to predict dependence of the flame spread rate on the ambient temperature was studied by carrying out a series of simulations with initial and ambient temperatures ranging from room temperature to $250{ }^{\circ} \mathrm{C}$. In each simulation, the initial temperature of the system was specified to be the same as the ambient temperature. Therefore, the simulations cannot capture the possible non-equilibrium starting conditions. Another source of uncertainty is related to the highest ambient temperatures. As shown by Fig. 8, the pyrolysis of wood starts around $250{ }^{\circ} \mathrm{C}$. In the experiments, the heating rate before the ignition is slow (in the order of $5 \mathrm{~K} / \mathrm{min}$ ) allowing the progress of pyrolysis before the sample is ignited. In the simulations, the sample is initially in a virgin state regardless of its initial temperature. This may lead to a reaction rate peak in the beginning of the simulation of $250{ }^{\circ} \mathrm{C}$ ambient temperature.

The predicted flame spread histories at different ambient temperatures are plotted in Fig. 10a. The duration of the initial acceleration phase is typically longer than what was observed in experiments and the flame spread rates in the end of this phase are higher than the measured ones. After the acceleration phase, a discontinuity point followed by a steady-state phase can be observed in all the curves. Similar behavior was not observed experimentally. The steady-state flame spread rates were determined by fitting straight lines to the parts of the curves following the discontinuity. Interestingly, the values are lower than the spread rates in the end of the acceleration phase. A comparison to the experimental results is shown in Fig. 10b. The simulation results' error bars reflect the uncertainty of fitting the straight lines. Straight lines fitted well to the data at low ambient temperatures but not as well when $T_{\infty} \geq 200{ }^{\circ} \mathrm{C}$. For the highest temperatures, better results could be obtained by making a simulation of a much taller sample. Considering the experimental and numerical uncertainties, the measured and simulated temperature dependences of the flame spread rate are in agreement.

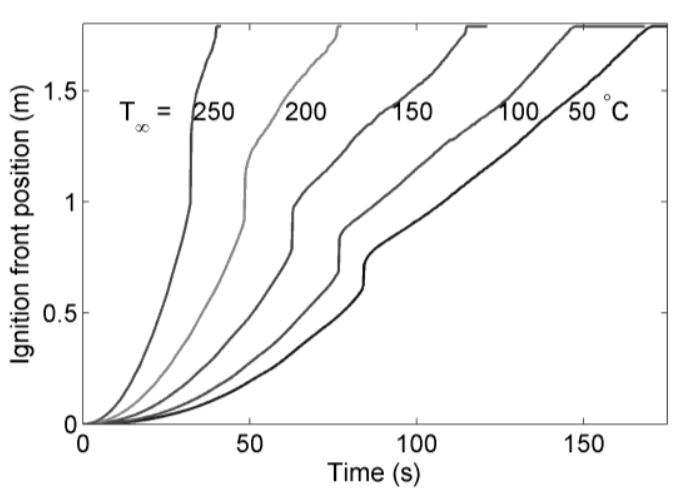

(a)

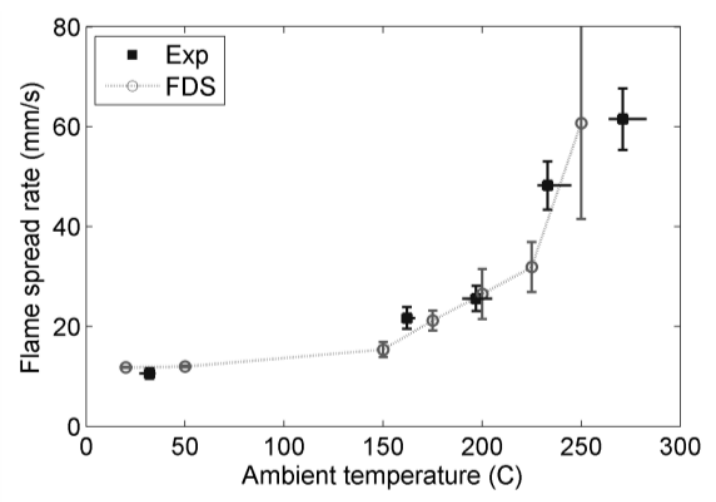

(b)

Fig. 10. (a) Position of the simulated ignition front in simulations at different ambient temperatures; (b) dependence of the flame spread rate on the temperature. 
An example of the burning rate vs. height along the sample surface at different times in the case of an ambient temperature of $100{ }^{\circ} \mathrm{C}$ is shown in Fig. 11. The shape of the curve does not reach a steady state during the simulation. The burning starts as a single peak traveling upwards, but at time $70 \mathrm{~s}$ from the ignition, the burnout of the ignition region takes place and a second peak appears to the upper end of the pyrolysis region. This event can be seen as the discontinuity of Fig. 10. The pyrolysis region is clearly longer than the experimental result of about $0.5 \mathrm{~m}$. It is interesting to note that a spread rate discontinuity was also predicted by the model of Grant and Drysdale [4]. One can speculate that if the burnout took place in the tail of the first peak, the simulated burning length would be in good agreement with the experiment. The burnout region shows strong fluctuations, for which there is no experimental evidence. The observed behavior may, at least partially, be explained by the nature of the combustion model: The mixture fraction combustion model will burn the combustible pyrolysis products even if the mass flux is very small. In reality, local flame extinction takes place at some point when the fuel mass flux is decreased.

According to the conventional theories of upward flame spread, the flame spread rate depends on the sample thickness through the level of flame heat flux, which in turn depends on the burning rate and length of the burning region. However, the current experimental results showed that the dependence is weak when the diameter is $8 \mathrm{~mm}$. This explains why the simulations were able to predict the flame spread rates relatively accurately, while failing in the prediction of the burning length. With thinner samples, the accuracy of the burning length prediction may be more important. This also indicates that the smalldiameter spread rate predictions in Fig. 9 have higher uncertainty than the predictions for the $8 \mathrm{~mm}$ sample.

The good agreement between the flame spread rate predictions and measurements justifies the use of the current model for the validation of pyrolysis models of more complicated samples, and for the research of the sub-grid scale (SGS) flame properties to be used in large eddy simulation (LES) of vertical flame spread. The SGS properties could include the components of the flame heat flux, gas temperatures and gas species concentrations.
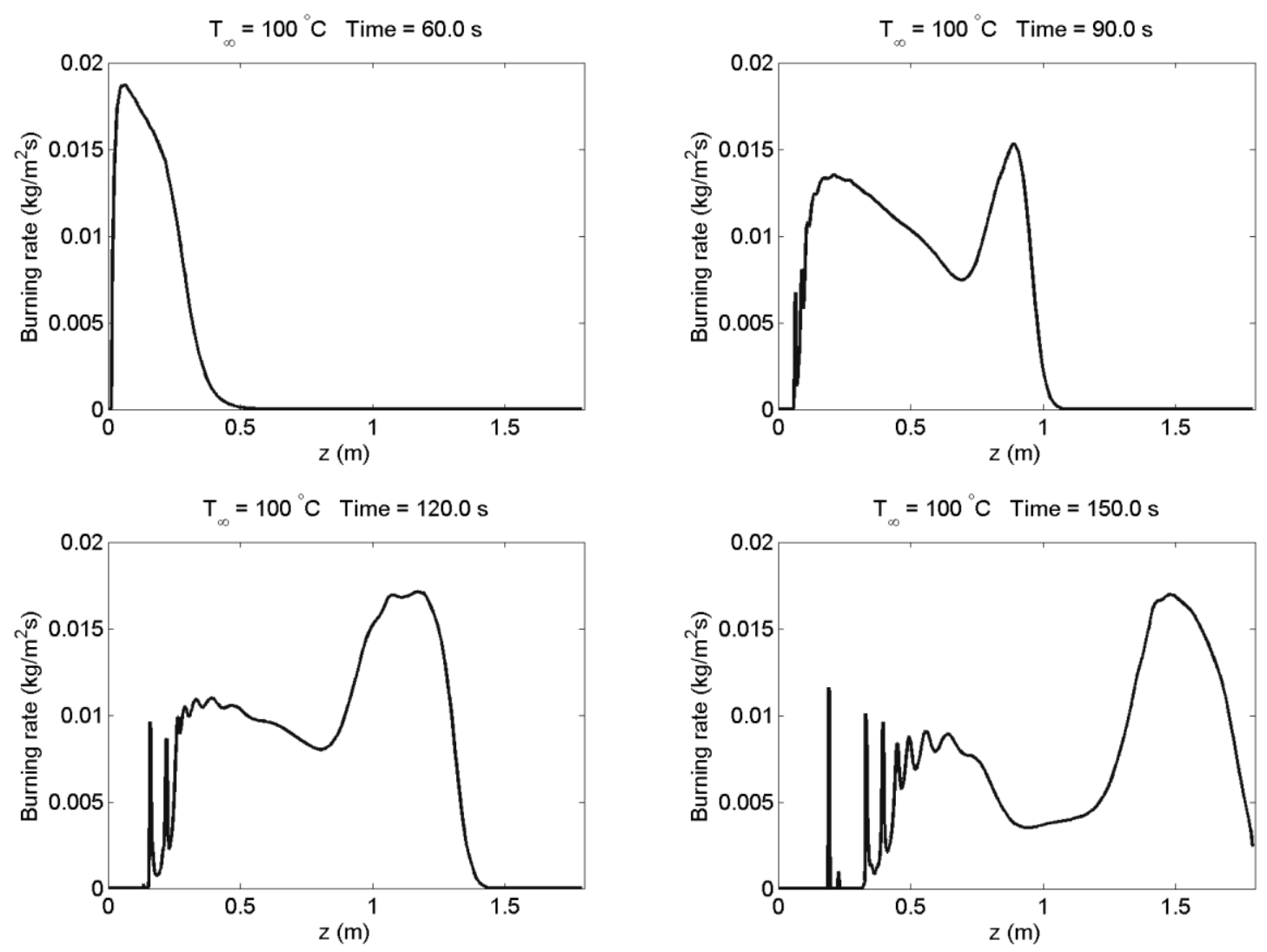

Fig. 11. Burning rate as a function of height at four times from the ignition, for $T_{\infty}=100{ }^{\circ} \mathrm{C}$. 


\section{CONCLUSIONS}

The features and function of a new apparatus for measuring flame spread on vertical samples at different initial and ambient temperatures are presented together with flame spread experiments on Birch wood and PVC cable samples. The experimental results for the flame spread rate on cylindrical Birch wood samples were $6.4-61.5 \mathrm{~mm} / \mathrm{s}$ in a temperature range of $22-271^{\circ} \mathrm{C}$. For PVC cable samples, the measured spread rates were $3.4-23.7 \mathrm{~mm} / \mathrm{s}$ in a temperature range of $23-190{ }^{\circ} \mathrm{C}$. The temperature dependence of the flame spread rate seems to be roughly exponential for both cylindrical Birch wood and PVC cable samples.

The symmetry of the flame propagation around the sample is essential for reliability of the experimental method because the temperature measurements are carried out in only one vertical rake. At least for samples of the diameter as in the current experiments, this requirement was fulfilled. The new flame spread apparatus seems to be appropriate for determining vertical flame spread as a function of temperature. We hope that this apparatus can be used for the risk assessment of existing and new types of electrical cables, for which the reduction of flame retardancy due to the increased temperature may be an issue.

Numerical simulations of the vertical flame spread on Birch wood were performed using axi-symmetric solutions of the reacting flow, coupled with a pyrolysis model, for which the parameters were estimated from small scale experiments. The agreement between the simulated and experimental flame spread rates was found to be good, with differences being of the same order as the uncertainties associated with the experiments and the determination of linear rate from the front location curve. These encouraging results motivate the use of the present model both for the validation of pyrolysis models of more complicated samples, and for the generation of SGS flame property models to be used in the LES of fire spread in engineering applications. More work is needed to improve the predictions of the pyrolysis length. This may require improvement both in the pyrolysis side and in the combustion reactions, to obtain a better description of the local flame extinction due to the shear and reducing fuel mass flux.

\section{ACKNOWLEDGEMENTS}

The authors wish to express their deepest gratitude to Dr Olavi Keski-Rahkonen, who envisaged and instigated the current research. The work has been partially funded by the State Nuclear Waste Management Fund (VYR). Protoshop Oy is acknowledged for detail design and construction of the apparatus.

\section{REFERENCES}

[1] Carrier, G.F., Fendell, F.E. and Feldman, P.S., (1980). Wind-Aided Flame Spread along a Horizontal Fuel Slab. Combustion Science and Technology, 23: 41-78. http://dx.doi.org/10.1080/00102208008952395

[2] Fernandez-Pello, A.C., (1978). A Theoretical Model for the Upward Laminar Spread of Flames over Vertical Fuel Surfaces. Combustion and Flame, 31: 135-148. http://dx.doi.org/10.1016/0010$\underline{2180(78) 90124-4}$

[3] Markstein, G.H. and de Ris, J., (1973). Upward Fire Spread over Textiles. Symposium (International) on Combustion, 14(1): 1085-1097. http://dx.doi.org/10.1016/S00820784(73)80098-0

[4] Grant, G. and Drysdale, D. D., (1995). Numerical Modelling of Early Flame Spread in Warehouse Fires, Fire Safety Journal, 24: 247-278. http://dx.doi.org/10.1016/0379-7112(95)00022-L

[5] Keski-Rahkonen, O. and Mangs, J., "Assessing of Flame Spread on NPP Cables," In Y. Zhou, S. $\mathrm{Yu} \& \mathrm{Y} . \mathrm{Xu}$ (eds.). Proceedings of the $18^{\text {th }}$ International Conference on Structural Mechanics in Reactor Technology. SMiRT 18. Atomic Energy Press. Beijing, 2005. Pp. 3972-3983.

[6] Keski-Rahkonen, O. and Mangs, J., "POTFIS Project Special Report - Experiments and Modelling on Vertical Flame Spread." Räty, H. and Puska, E. K. (ed.). 2004. SAFIR, The Finnish Research Programme on Nuclear Power Plant Safety 2003-2006, Interim Report, VTT Research Notes 2272. VTT Processes, Espoo, 2005, pp. 257-265. 
[7] Hostikka, S., Matala, A., Mangs, J. and Hietaniemi, J., "Implementation of Quantitative Fire Risk Assessment in PSA (FIRAS). FIRAS Summary Report.” Puska, E.K. (ed.) SAFIR2010. The Finnish Research Programme on Nuclear Power Plant Safety 2007-2010. Interim Report. VTT Research Notes 2466. VTT. Espoo, 2009, pp. 495 - 505.

[8] Mangs, J., “A New Apparatus for Flame Spread Experiments.” VTT Working Papers 112. VTT, Espoo, 2009, 51 p. + App. 28 p.

[9] Xie, W. and DesJardin, P.E., (2009) An Embedded Upward Flame Spread Model using 2D Direct Numerical Simulations, Combustion and Flame, 156: 522-530. http://dx.doi.org/10.1016/j.combustflame.2008.11.011

[10] McGrattan, K., Hostikka, S., Floyd, J., Baum, H., Rehm, R., Mell, W. and McDermott, R., "Fire Dynamics Simulator (Version 5) Technical Reference Guide." Volume 1: Mathematical Model. National Institute of Standards and Technology, Gaithersburg, MD, October 2007. NIST Special Publication 1018-5.

[11] Hasemi, Y., "Surface Flame Spread," The SFPE Handbook of Fire Safety Engineering, (4 $4^{\text {th }}$ ed.) DiNenno P. (ed.), Quincy, MA, 2008. p. 2/278-2/290.

[12] Ritchie, S.J., Steckler, K.D., Hamins, A., Cleary, T.G., Yang, J.C. and Kashiwagi, T. 1997. Effect of Sample Size on the Heat Release Rate of Charring Materials. Fire Safety Science 5:177-188. http://dx.doi.org/10.3801/IAFSS.FSS.5-177

[13] Matala, A., Hostikka, S. and Mangs, J. 2009. Estimation of Pyrolysis Model Parameters for Solid Materials using Thermogravimetric Data. Fire Safety Science 9:1213-1223. http://dx.doi.org/10.3801/IAFSS.FSS.9-1213

[14] Lautenberger, C.W., A Generalized Pyrolysis Model for Combustible Solids. Ph.D. Dissertation, Department of Mechanical Engineering, University of California at Berkeley, CA, 2007. 